\title{
Reducing stiffness of shock-absorbing pylon amplifies prosthesis energy loss and redistributes joint mechanical work during walking
}

\author{
Jenny Anne Maun', Steven A. Gard ${ }^{2,3,4}$, Matthew J. Major ${ }^{2,3,4 \dagger}$ and Kota Z. Takahashi ${ }^{{ }^{*+}}$
}

\begin{abstract}
Background: A shock-absorbing pylon (SAP) is a modular prosthetic component designed to attenuate impact forces, which unlike traditional pylons that are rigid, can compress to absorb, return, or dissipate energy. Previous studies found that walking with a SAP improved lower-limb prosthesis users' comfort and residual limb pain. While longitudinal stiffness of a SAP has been shown to affect gait kinematics, kinetics, and work done by the entire lower limb, the energetic contributions from the prosthesis and the intact joints have not been examined. The purpose of this study was to determine the effects of SAP stiffness and walking speed on the mechanical work contributions of the prosthesis (i.e., all components distal to socket), knee, and hip in individuals with a transtibial amputation.
\end{abstract}

Methods: Twelve participants with unilateral transtibial amputation walked overground at their customary $\left(1.22 \pm 0.18 \mathrm{~ms}^{-1}\right)$ and fast speeds $\left(1.53 \pm 0.29 \mathrm{~ms}^{-1}\right)$ under four different levels of SAP stiffness. Power and mechanical work profiles of the leg joints and components distal to the socket were quantified. The effects of SAP stiffness and walking speed on positive and negative work were analyzed using two-factor (stiffness and speed) repeated-measure ANOVAs $(a=0.05)$.

Results: Faster walking significantly increased mechanical work from the SAP-integrated prosthesis $(p<0.001)$. Reducing SAP stiffness increased the magnitude of prosthesis negative work (energy absorption) during early stance $(p=0.045)$ by as much as $0.027 \mathrm{Jkg}^{-1}$, without affecting the positive work (energy return) during late stance $(p=0.159)$, suggesting a damping effect. This energy loss was partially offset by an increase in residual hip positive work (as much as $0.012 \mathrm{Jgg}^{-1}$ ) during late stance $(p=0.045)$. Reducing SAP stiffness also reduced the magnitude of negative work on the contralateral sound limb during early stance by $11-17 \%(p=0.001)$.

Conclusions: Reducing SAP stiffness and faster walking amplified the prostheses damping effect, which redistributed the mechanical work, both in magnitude and timing, within the residual joints and sound limb. With its capacity to absorb and dissipate energy, future studies are warranted to determine whether SAPs can provide additional user benefit for locomotor tasks that require greater attenuation of impact forces (e.g., load carriage) or energy dissipation (e.g., downhill walking).

\footnotetext{
*Correspondence: ktakahashi@unomaha.edu

${ }^{\dagger}$ Matthew J. Major and Kota Z. Takahashi are joint last author/equal contribution

${ }^{1}$ Department of Biomechanics, University of Nebraska at Omaha, Omaha, NE, USA

Full list of author information is available at the end of the article
}

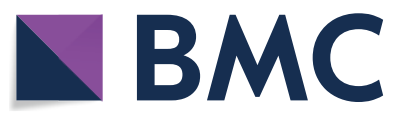

(c) The Author(s) 2021. Open Access This article is licensed under a Creative Commons Attribution 4.0 International License, which permits use, sharing, adaptation, distribution and reproduction in any medium or format, as long as you give appropriate credit to the original author(s) and the source, provide a link to the Creative Commons licence, and indicate if changes were made. The images or other third party material in this article are included in the article's Creative Commons licence, unless indicated otherwise in a credit line to the material. If material is not included in the article's Creative Commons licence and your intended use is not permitted by statutory regulation or exceeds the permitted use, you will need to obtain permission directly from the copyright holder. To view a copy of this licence, visit http://creativecommons.org/licenses/by/4.0/. The Creative Commons Public Domain Dedication waiver (http://creativeco mmons.org/publicdomain/zero/1.0/) applies to the data made available in this article, unless otherwise stated in a credit line to the data. 
Keywords: Amputation, Gait, Biomechanics, Power, Damping, Dissipation, Absorption

\section{Background}

Daily activities, like walking, are common challenges experienced by individuals with a lower-limb amputation [1-5]. Individuals with an amputation seek a prosthesis that allows both mobility and comfort [5-7]. While considerable attention has been paid to studying the effects of prosthetic feet [8-10] and ankle components [11-18], relatively less is known regarding the effects of prosthetic pylons on mobility outcomes. A shock-absorbing pylon (SAP), in particular, is a modular component designed to attenuate impact forces to assist with weight acceptance $[7,19-21]$. Unlike traditional pylons that rigidly connect from the socket to the distal foot and ankle components, SAPs comprise of a telescoping shank with viscoelastic properties that can compress $[19,22,23]$ and/ or twist about the longitudinal axis [24, 25]. Prior studies have suggested that wearing a prosthesis with a SAP can improve user comfort and reduce residual limb pain compared to walking with a rigid pylon [19, 22]. However, there is currently limited knowledge regarding how SAPs directly affect the prostheses' 'shock-absorbing' capabilities-in particular, the mechanical work done on the prosthesis which relates to the energy absorption, storage, and/or return during walking.

Mechanical work done on the SAP is influenced by the forces acting on the pylon and its stiffness, which affects the SAP's longitudinal displacement. Prior studies involving SAPs have revealed their capacity for influencing the forces transmitted to the legs during walking $[19,22]$. For example, walking with a SAP reduced ground reaction force magnitudes during early stance, especially at speeds greater than $1.3 \mathrm{~ms}^{-1}[19,22]$. Such force attenuation may theoretically influence energy absorption during early stance (also termed 'collision work'), which relates to the mechanics of the leading leg as weight is being transferred from the trailing leg [26]. However, the work done by SAP-integrated prostheses have not been directly quantified. While the anatomical ankle-foot structures have natural shock-absorbing mechanisms, such as the heel pad [27-29] and ankle muscles [30, $31]$, it is currently unclear whether the SAPs contribute directly to energy absorption during collision.

A recent study analyzed the work of the center-of-mass (or individual limbs) when participants walked with SAPs of various stiffness [32]. Results from that study suggested reducing pylon stiffness increased the magnitude of prosthetic limb negative work during early stance (i.e., collision work) and enhanced prosthetic limb positive work during late stance (i.e., push-off work) [32]. While this study established the SAP's potential to affect the work done on the center-of-mass, the relative work contributions of the prosthesis and the intact joints remain unknown. Partitioning the work contributions may reveal additional insights regarding the interaction between the user and the prosthesis-specifically, how changes in SAP stiffness directly affect prosthesis energetics and indirectly affect compensations at the intact joints. For example, prior studies in prosthetic foot and ankle components have revealed that the energetics of the prostheses can directly affect ipsilateral or residual hip joint kinematics and kinetics [33-35] and collision work on the contralateral sound limb $[9,11]$. Thus, quantifying work contributions during various phases of stance within and across the lower limbs, including the prosthesis components and the intact joints, is expected to reveal greater insights about the effects of SAP-integrated prostheses on walking outcomes.

The purpose of our study was to determine the effect of SAP stiffness and walking speed on the mechanical work contributions from the prosthesis (i.e., components distal to the socket), proximal intact joints (residual knee and hip), and the contralateral sound limb of individuals with a unilateral transtibial amputation. Based on similar studies involving prosthetic ankle stiffness $[9,16,33]$, we hypothesized that reducing SAP stiffness would increase the magnitude of negative work during early stance and positive work in late stance within the prosthesis-which would indicate greater energy stored and returned, respectively. Assuming that the mechanical work within a leg is conserved (i.e., the net work is near zero during steady-state walking), we expected the proximal leg joints to act in opposition to the prosthesis behavior. We hypothesized that reducing SAP stiffness would decrease the residual knee and hip joints' magnitudes of negative work during early stance and positive work during late stance. Lastly, we hypothesized that faster walking speed will reveal greater effects of stiffness on the prosthesis, residual knee, and residual hip work to correspond with increased ground reaction forces.

\section{Methods \\ Participants}

A secondary analysis was performed on a dataset from a previous study [23] that included 12 participants with unilateral transtibial amputation (4 females/8 males; age: $48.9 \pm 17.9$ years; height: $1.80 \pm 0.10 \mathrm{~m}$; mass: $84.8 \pm 21.0 \mathrm{~kg}$; time since amputation: $12.8 \pm 8.9 \mathrm{yrs})$. All participants had at least six months of experience walking 
with their current prosthesis and were able to walk independently without assistance for at least $10 \mathrm{~m}$. All participants provided written, informed consent to participate. Northwestern University Institutional Review Board approved this study.

\section{Protocol}

In the original study from Boutwell et al. [23], participants walked overground along a $10 \mathrm{~m}$ level walkway at two self-paced walking speeds (customary-1.22 \pm 0.18 and fast $-1.53 \pm 0.29 \mathrm{~ms}^{-1}$; means \pm SD) under four stiffness conditions: SOFT, MED, NORM, and RIGID. Participants walked at both speeds while first wearing the NORM stiffness as the control condition to obtain a baseline speed. The rest of the stiffness conditions were randomized and walking speed was controlled through instantaneous measurement and verbal feedback to be within $\pm 10 \%$ of their baseline walking speed. Participants walked back and forth along a $10 \mathrm{~m}$ walkway until 5 clean force plate strikes were obtained from both limbs, defined as a single foot landing within the boundaries of a single force plate (AMTI, Watertown, MA). More detailed information on the experimental protocol can be found in the Boutwell study [23]. Participants walked in their prescribed socket and suspension system, while all components distal to the socket (i.e., the experimental prosthesis) were the same for all participants during the experiment. The components of the experimental prosthesis were the SAP (Endolite Telescoping Torsion Pro; Endolite, Miamisburg, $\mathrm{OH}$ ) and a standard prosthetic foot (Seattle Lightfoot; Trulife, Dublin, Ireland) inserted into flat shoes with minimal sole thickness to control and minimize footwear effects [36]. The Endolite Telescoping Torsion Pro SAP was equipped with interchangeable springs to modify the longitudinal stiffness of the pylon. The torsion, or twisting, of the SAP (i.e., transverse motion) was disabled to focus on the pylon's longitudinal stiffness. Prostheses were fitted and aligned by a certified prosthetist. Participants were given at least five minutes of walking to familiarize to each prosthesis configuration.

All stiffness conditions were a percentage of the manufacturer-recommended NORM stiffness: SOFT (50\% of NORM), MED (75\% of NORM stiffness), and RIGID (above NORM stiffness (Table 1) [23, 32]. The RIGID stiffness comprised of a steel rod inside the SAP instead of a spring to stop pylon displacement. One spring set was assigned to a participant by associating the NORM stiffness based on their body mass and activity level, with spring set 2 slightly stiffer than spring set 1 . Five participants were assigned to spring set 1 (mass: $71.9 \pm 5.04 \mathrm{~kg}$; means $\pm \mathrm{SD})$ and seven participants were assigned to spring set 2 (mass: $99.1 \pm 19.1 \mathrm{~kg}$ ).

\section{Data analysis}

A modified Helen Hayes full-body marker set [37] with 24 markers were applied. Lower-limb kinematic and kinetic data were collected using a 12-camera motion capture system (Motion Analysis Corporation, Rohnert Park, CA) at $240 \mathrm{~Hz}$ and 6 floor-embedded force plates (Advanced Mechanical Technology, Inc. Watertown, MA) captured at $1920 \mathrm{~Hz}$. Kinematic and kinetic data were processed using Visual3D (C-Motion, Inc., Germantown, MD) and were filtered using a low-pass Butterworth filter with a frequency cut-off of $6 \mathrm{~Hz}$ and $25 \mathrm{~Hz}$, respectively. The analysis was performed on all available foot strikes for each stiffness and speed condition, verified visually in Visual3D through foot contact within the border of a single force plate and via analyses of centerof-pressure location relative to the foot's geometry.

Mechanical powers $\left(\mathrm{Wkg}^{-1}\right)$ from all prosthetic components distal to the socket (i.e., the prosthesis) and ankle-foot complex of the sound limb were calculated using the unified deformable power analysis [38]. Knee and hip joint power from both limbs were calculated using a six degree-of-freedom joint power analysis, which takes into account the three degrees of rotation and the three degrees of translation about a joint $[39,40]$. A prior study indicated that including all six degree-offreedom improves the accuracy of the total work done on the whole-body, compared to a more traditional three degree-of-freedom analysis [40]. Total limb power was estimated as the sum of the prosthesis or sound limb ankle-foot complex, knee, and hip power, which captured the rate of energy change at the center-of-mass [40]. The time-series profile of the total limb power was used to identify four sub-phases of stance $[40,41]$ where the start and end of each sub-phase was defined as the instance when total limb power was zero, or crossed the $\mathrm{x}$-axis (Fig. 1). The sub-phases were defined as: (1) collision-negative power and work during early stance, (2)

Table 1 The four stiffness conditions and their values for each spring set were measured by mechanical testing from Boutwell et al. [23]

\begin{tabular}{llllll}
\hline Stiffness condition & SOFT $\left(\mathbf{k N m}^{-\mathbf{1}}\right)$ & MED $\left(\mathbf{k N m}^{-\mathbf{1}}\right)$ & NORM $\left(\mathbf{k N m}^{-\mathbf{1}}\right)$ & RIGID $\left(\mathbf{k N m}{ }^{-\mathbf{1}}\right)$ & Average mass $(\mathbf{k g})$ \\
\hline Spring set 1 & 68.2 & 89.3 & 111.8 & 3556.9 & $71.9 \pm 5.04$ \\
Spring set 2 & 85.6 & 111.8 & 153.8 & 3556.9 & $99.1 \pm 19.1$ \\
\hline
\end{tabular}



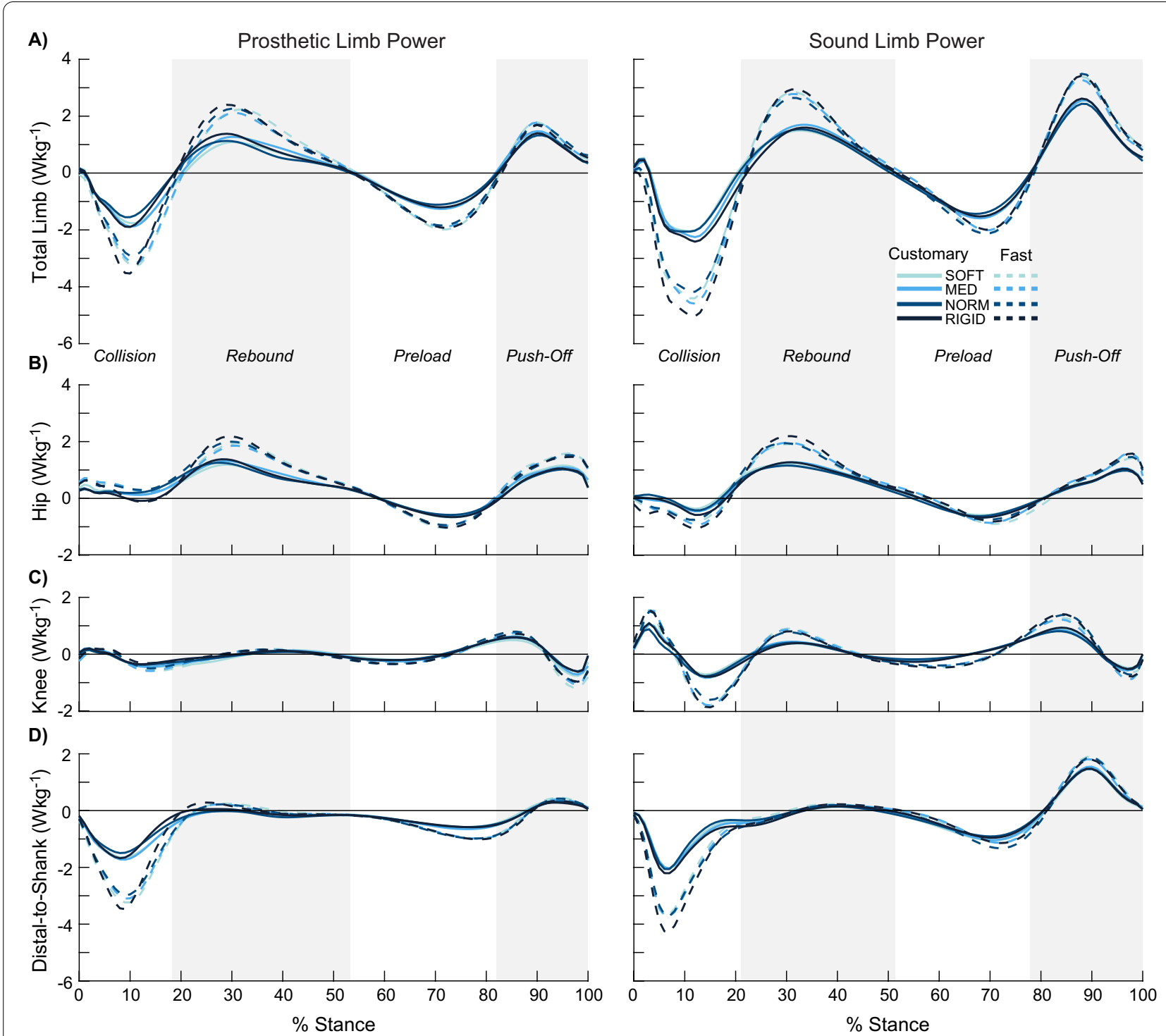

Fig. 1 Lower limb power. Average time-series of power $\left(\mathrm{Wkg}^{-1}\right)$ during stance phase $(n=12)$ were computed for each stiffness (light blue $=$ SOFT to dark blue $=$ RIGID) and speed (solid line $=$ customary speed, dotted line = fast speed). Sub-phases (collision, rebound, preload, and push-off) are divided by gray panels and determined when total limb power crosses zero. Prosthesis limb power is on the left column and sound limb power is on the right column. Total limb power $(\mathbf{A})$ is the sum of the powers at the hip (B), knee $(\mathbf{C})$, and prosthesis or distal-to-shank (D)

rebound-positive power and work during early-to-mid stance, (3) preload-negative power and work during mid-to-late stance, and (4) push-off-positive power and work during late stance.

Positive, negative, and net mechanical work $\left(\mathrm{Jkg}^{-1}\right)$ of the prosthesis, ankle-foot complex, knee, hip, and total limb across entire stance and each sub-phase (determined by the total limb power) were calculated by integrating power with respect to time using custom MATLAB code (Mathworks, Natick, MA). All kinetic variables (power and work) were normalized by body mass (kg).

\section{Prosthesis analysis}

To further partition the contributions from the prosthesis components, we quantified the work done by the pylon compression. Power from pylon compression was calculated as the product between the force along the longitudinal axis (i.e., ground reaction force transformed from the laboratory to shank's coordinate system [42]) and the compression velocity. The compression velocity of the pylon was computed as the derivative of the pylon's displacement, or the length of the pylon during the entire stance phase. The length of the pylon was calculated 
using the distance formula between two points in a 3D coordinate system. The two markers were placed on the front-facing portion of the pylon: at the top of the pylon (located just below the prosthetic socket) and at the bottom of the pylon (located just above the prosthetic foot at the "ankle" location). About $25 \mathrm{~cm}$ of space was needed between the socket and the ground to fit the pylon and prosthetic foot [23]. Work from the pylon compression was quantified as the time-integral of the compression power during the entire stance phase. The power contribution due to prosthetic twisting was not included in the analysis as the transverse motion of the pylon was disabled. It is important to note that the prosthesis analyses did not account for the residuum-socket interface.

\section{Statistical analysis}

Two-factor (stiffness and speed) repeated-measures analysis of variance (ANOVA) assessed the main effects of SAP stiffness and walking speed on the positive and negative mechanical work variables of both prosthetic and sound legs (prosthesis or ankle-foot complex, knee, hip, and total limb), with the critical $\alpha$ of 0.05 . The two-factor ANOVA also assessed the interaction effects between stiffness and speed, to determine whether the influence of SAP stiffness on mechanical work varied between the two self-paced walking speeds. Data normality and sphericity was confirmed using the Shapiro-Wilk and Mauchly tests, respectively. A Greenhouse-Geisser correction was implemented when sphericity was violated. If the main effect of stiffness was significant, multiple post-hoc pairwise comparisons were conducted with a Bonferroni correction to account for Type-I error risk. If the interaction effects were significant, the simple main effect of stiffness was assessed by calculating the estimated marginal means of each stiffness while holding each speed constant using a one-factor (stiffness) ANOVA. Additionally, two-factor (stiffness and speed) repeated-measures ANOVA were used to assess the main and interaction effects of SAP stiffness and walking speed on the positive and negative mechanical work of the prosthesis due to pylon compression, with a critical $\alpha$ of 0.05 . Statistical analyses were conducted using SPSS (IBM, Chicago, IL). Due to the exploratory nature of our analyses, we did not perform any $\alpha$ level adjustments as a result of multiple hypotheses testing. However, we reported all p-values and effect sizes (computed as partial eta squared, $\eta_{p}^{2}$ ) for full transparency of the results.

\section{Results}

\section{Total prosthetic limb (prosthesis + knee + hip)}

There were no stiffness effects on positive and negative work in the entire stance phase $\left(\mathrm{p} \geq 0.115, \eta^{2} \leq 0.162\right.$, Fig. 2A, B). While the rebound $\left(\mathrm{p} \geq 0.056, \eta_{p}^{2} \leq 0.202\right.$,
Fig. 2D), preload ( $\mathrm{p} \geq 0.635, \eta^{2} \leq 0.050$, Fig. $2 \mathrm{E}$ ), and push-off ( $\mathrm{p} \geq 0.058, \eta^{2} \leq 0.204$, Fig. $\left.2 \mathrm{~F}\right)$ sub-phases were not significant, negative collision work showed a stiffness effect ( $\mathrm{p}=0.041, \eta_{p}^{2}=0.219$, Fig. $2 \mathrm{C}$ ). There were no significant post-hoc pairwise comparisons for negative collision work ( $\mathrm{p} \geq 0.152)$.

There were speed effects for both positive and negative work in the entire stance phase $\left(\mathrm{p} \leq 0.005, \eta^{2} \leq 0.668\right.$, Fig. 2B). Fast walking was associated with increased stance work: $27 \%$ greater positive and $34 \%$ greater negative stance work compared to customary walking. Apart from the push-off sub-phase ( $\left.\mathrm{p} \geq 0.473, \eta_{p}^{2} \leq 0.048\right)$, all other sub-phases showed speed effects $(\mathrm{p} \leq 0.019)$. Fast walking was also associated with increased sub-phase work: $45 \%$ greater negative collision work $(p=0.006$, $\left.\eta_{p}^{2}=0.511\right), \quad 44 \%$ greater positive rebound work $\left(\mathrm{p}<0.001, \eta^{2}{ }_{p}=0.686\right)$, and $24 \%$ greater negative preload work $\left(\mathrm{p}=0.019, \eta_{p}^{2}=0.405\right)$ compared to customary walking.

There was an interaction effect for only positive work in the entire stance phase $\left(\mathrm{p}=0.009, \eta^{2}=0.293\right)$. Simple main effects analysis for positive stance work revealed no stiffness effect $\left(\mathrm{p} \geq 0.92, \eta^{2}{ }_{p} \leq 0.005\right)$; however, speed effects were observed in SOFT $(\mathrm{p}=0.026$, $\left.\eta_{p}^{2}=0.055\right)$ and NORM $\left(\mathrm{p}=0.013, \eta_{p}^{2}=0.068\right)$ stiffness conditions, where fast walking led to $30-35 \%$ greater positive stance work. While the collision ( $\mathrm{p} \geq 0.167$, $\eta_{p}^{2} \leq 0.152$ ), preload ( $\mathrm{p} \geq 0.347, \eta_{p}^{2} \leq 0.083$ ), and push-off $\left(\mathrm{p} \geq 0.325, \eta_{p}^{2} \leq 0.089\right)$ sub-phases had non-significant interaction effects, this effect was significant for positive rebound work $\left(\mathrm{p}=0.019, \eta_{p}^{2}=0.311\right)$. Simple main effects analysis for positive rebound work revealed no stiffness effect $\left(\mathrm{p} \geq 0.87, \eta^{2}{ }_{p} \leq 0.008\right)$; however, speed effects were observed in SOFT $\left(\mathrm{p}=0.017, \eta^{2}=0.063\right)$, NORM $\left(\mathrm{p}=0.015, \eta_{p}^{2}=0.066\right)$, and RIGID $(\mathrm{p}=0.043$, $\left.\eta_{p}^{2}=0.046\right)$ stiffness conditions, where fast walking was associated with $39-56 \%$ greater positive rebound work.

\section{Prosthesis (distal to the socket)}

There were no stiffness effects on positive and negative work in the entire stance phase $\left(\mathrm{p} \geq 0.192, \eta^{2} \leq 0.329\right.$, Fig. 3A, B). Apart from the rebound $(\mathrm{p} \geq 0.236$, $\eta_{p}^{2} \leq 0.119$, Fig. 3D), preload $\left(\mathrm{p} \geq 0.426, \quad \eta^{2} \leq 0.067\right.$, Fig. 3E), and push-off ( $\mathrm{p} \geq 0.159, \eta^{2} \leq 0.143$, Fig. 3F) subphases, negative collision work showed a stiffness effect $\left(\mathrm{p}=0.045, \eta_{p}^{2}=0.212\right.$, Fig. $\left.3 \mathrm{C}\right)$. There were no significant post-hoc pairwise comparisons for negative collision work $(\mathrm{p} \geq 0.163)$.

There were speed effects for both positive and negative work in the entire stance phase $\left(\mathrm{p} \leq 0.017, \eta^{2}{ }_{p} \leq 0.592\right)$. Fast walking was associated with increased stance work: $43 \%$ greater positive and $36 \%$ greater negative stance work compared to customary walking. All sub-phases 


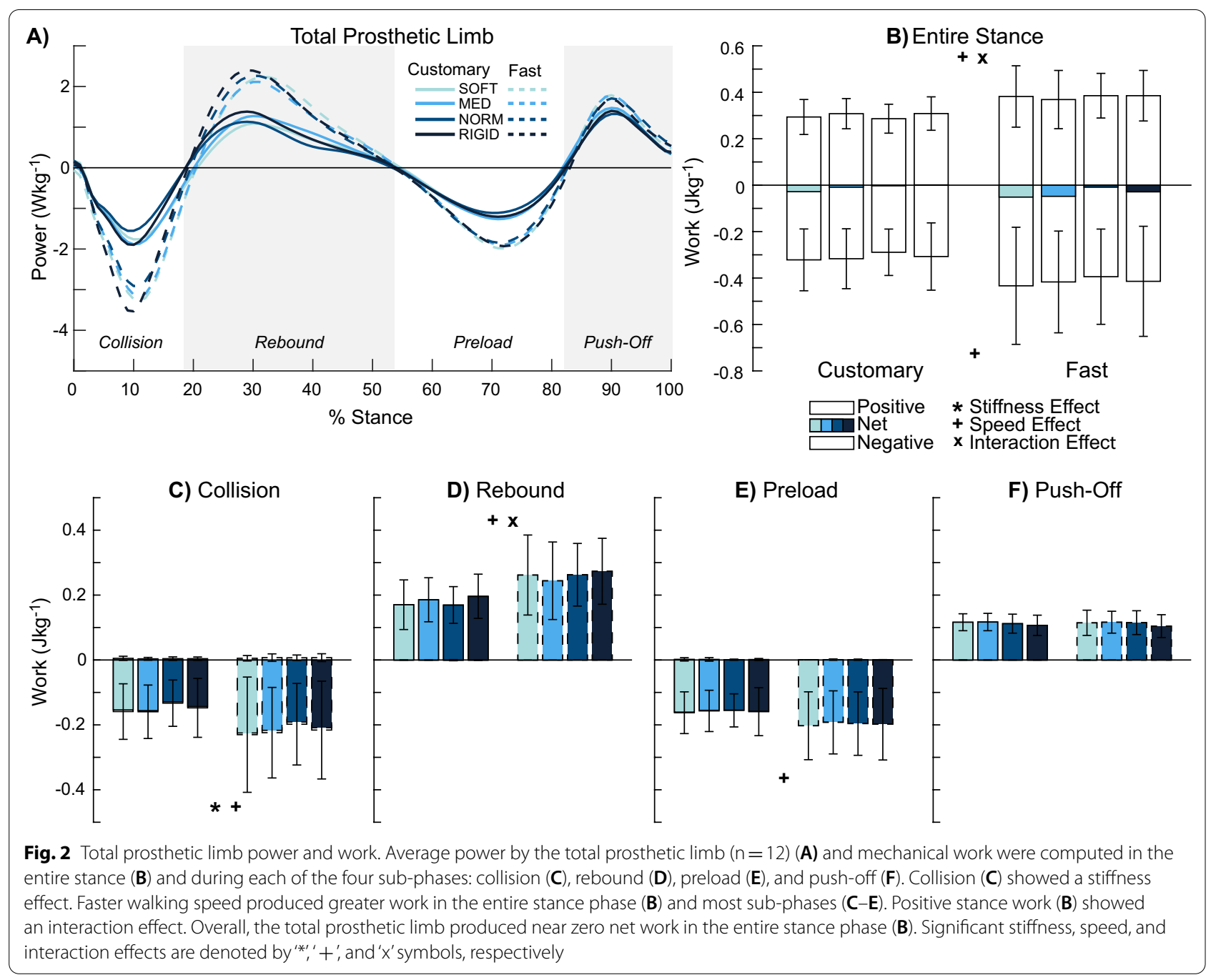

apart from the push-off phase ( $\left.\mathrm{p} \geq 0.075, \eta_{p}^{2} \leq 0.260\right)$, showed speed effects $(\mathrm{p} \leq 0.017)$. Fast walking was also associated with increased sub-phase work: $55 \%$ greater negative collision work $\left(\mathrm{p}=0.002, \eta_{p}^{2}=0.612\right), 117 \%$ greater positive rebound work $\left(\mathrm{p}=0.004, \eta_{p}^{2}=0.537\right)$, and $24 \%$ greater negative preload work $(\mathrm{p}=0.010$, $\left.\eta_{p}^{2}=0.466\right)$ compared to customary walking.

There were no interaction effects in the entire stance phase $\left(\mathrm{p} \geq 0.791, \eta^{2}{ }_{p} \leq 0.031\right)$ and sub-phases $(\mathrm{p} \geq 0.389$, $\left.\eta_{p}^{2} \leq 0.080\right)$.

\section{Residual knee}

There was a stiffness effect for only negative work in the entire stance phase ( $\mathrm{p}=0.03, \eta^{2}=0.312$, Fig. $\left.4 \mathrm{~A}, \mathrm{~B}\right)$. One post-hoc pairwise comparison was significant (SOFTNORM $\mathrm{p}=0.025)$, where reduced stiffness produced $16 \%$ greater negative work during the entire stance phase. The rebound ( $\mathrm{p} \geq 0.345, \eta_{p}^{2} \leq 0.094$, Fig. 4D), preload $\left(\mathrm{p} \geq 0.585, \eta^{2}{ }_{p} \leq 0.043\right.$, Fig. 4E), and push-off $(\mathrm{p} \geq 0.097$, $\eta_{p}^{2} \leq 0.172$, Fig. 4F) sub-phases did not have a significant stiffness effect, but it was significant for negative collision work ( $\mathrm{p}=0.001, \eta_{p}^{2}=0.395$, Fig. $\left.4 \mathrm{C}\right)$. Two post-hoc pairwise comparisons were significant (MED-NORM $\mathrm{p}=0.007$, MED-RIGID $\mathrm{p}=0.007)$ where reduced stiffness produced $25-47 \%$ more negative collision work.

There was a speed effect for only negative work in the entire stance phase $\left(\mathrm{p}=0.006, \eta_{p}^{2}=0.505\right)$. Fast walking was associated with $24 \%$ greater negative stance work compared to customary walking. Apart from the rebound $\left(\mathrm{p} \geq 0.167, \eta^{2}{ }_{p} \leq 0.166\right)$ and preload $\left(\mathrm{p} \geq 0.22, \eta^{2} \leq 0.133\right)$ sub-phases, positive and negative collision work and negative push-off work showed speed effects $(\mathrm{p} \leq 0.041)$. Fast walking was also associated with increased subphase work: $111 \%$ greater positive collision $(\mathrm{p}=0.016$, $\left.\eta^{2}=0.423\right)$ and $28 \%$ greater negative collision $(\mathrm{p}=0.041$, $\eta^{2}{ }_{p}=0.327$ ) work and $33 \%$ greater negative push-off work $\left(\mathrm{p}=0.016, \eta_{p}^{2}=0.426\right)$ compared to customary walking. 


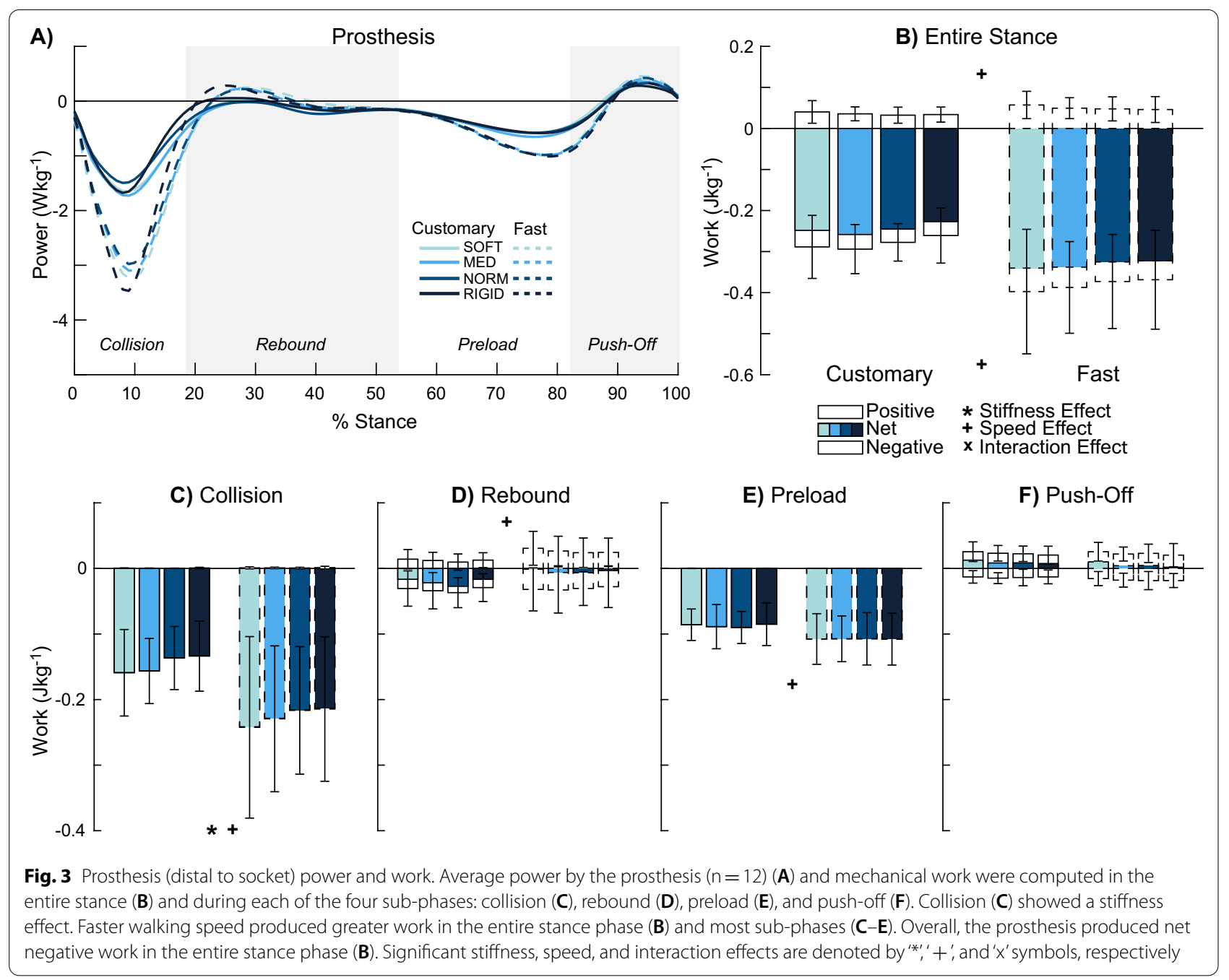

There were no interaction effects in the entire stance phase $\left(\mathrm{p} \geq 0.584, \eta_{p}^{2} \leq 0.056\right)$ and sub-phases $(\mathrm{p} \geq 0.184$, $\left.\eta_{p}^{2} \leq 0.135\right)$.

\section{Residual hip}

There was a stiffness effect for only negative work in the entire stance phase $\left(\mathrm{p}=0.007, \eta^{2}=0.305\right.$, Fig. 5A, B). There were no significant post-hoc pairwise comparisons ( $p \geq 0.065$ ) for negative stance work. While the rebound $\left(\mathrm{p} \geq 0.238, \eta_{p}^{2} \leq 0.118\right.$, Fig. 5D) and preload ( $\mathrm{p} \geq 0.172$, $\eta_{p}^{2} \leq 0.139$, Fig. 5E) sub-phases were not significant, positive collision ( $\mathrm{p}<0.001, \eta_{p}^{2}=0.558$, Fig. $5 \mathrm{C}$ ) and positive push-off $\left(\mathrm{p}=0.045, \eta_{p}^{2}=0.214\right.$, Fig. 5F) work showed stiffness effects $(\mathrm{p} \leq 0.045)$. Four post-hoc pairwise comparisons were significant (SOFT-MED $p=0.044$, SOFTRIGID $\mathrm{p}=0.005$, MED-RIGID $\mathrm{p}=0.006$, NORM-RIGID $\mathrm{p}=0.019$ ), where reduced stiffness was associated with $21-73 \%$ greater positive collision work. However, there were no significant post-hoc pairwise comparisons for positive push-off work ( $\mathrm{p} \geq 0.158)$.

There were speed effects for only positive work in the entire stance phase $\left(\mathrm{p}<0.001, \eta_{p}^{2}=0.703\right)$. Fast walking was associated with $28 \%$ greater positive stance work compared to customary walking. Apart from the preload sub-phase $\left(\mathrm{p} \geq 0.163, \eta^{2}{ }_{p} \leq 0.169\right)$, all other sub-phases showed speed effects $(\mathrm{p} \leq 0.015)$. Fast walking was also associated with increased positive sub-phase work: $49 \%$ greater positive collision work $\left(\mathrm{p}=0.007, \eta_{p}^{2}=0.503\right)$, $31 \%$ greater positive rebound work $(\mathrm{p}=0.001$, $\left.\eta_{p}^{2}=0.641\right)$, and $17 \%$ greater positive push-off work $\left(\mathrm{p}=0.015, \eta_{p}^{2}=0.429\right)$ compared to customary walking. However, fast walking also associated with less negative work: $94 \%$ less negative push-off work $(\mathrm{p}=0.045$, $\left.\eta^{2}=0.317\right)$ compared to customary walking.

There were no interaction effects in the entire stance phase $\left(\mathrm{p} \geq 0.348, \eta^{2} \leq 0.091\right)$ and sub-phases $(\mathrm{p} \geq 0.13$, $\left.\eta_{p}^{2} \leq 0.155\right)$. 


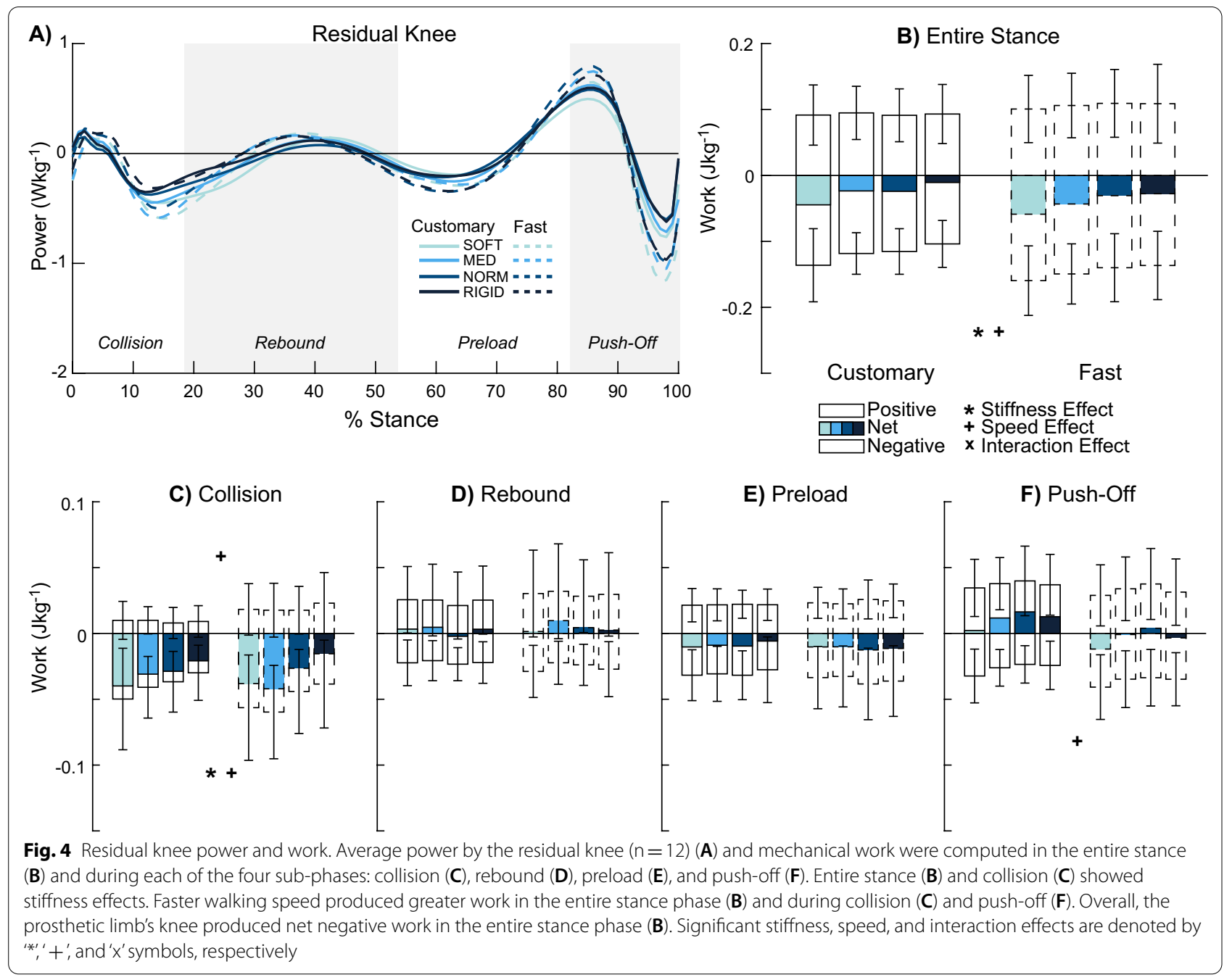

Total sound limb (ankle-foot + knee + hip)

There were no stiffness effects in the entire stance phase $\left(\mathrm{p} \geq 0.057, \eta_{p}^{2} \leq 0.201\right.$, Fig. 6A, B). While the rebound $\left(\mathrm{p} \geq 0.240, \quad \eta^{2} \leq 0.118\right.$, Fig. 6D), preload $(\mathrm{p} \geq 0.123$, $\eta_{p}^{2} \leq 0.159$, Fig. 6E), and push-off ( $\mathrm{p} \geq 0.307, \eta^{2} \leq 0.095$, Fig. 6F) sub-phases were not significant, negative collision work showed a stiffness effect $\left(\mathrm{p}=0.001, \eta^{2}{ }_{p}=0.396\right.$, Fig. 6C). Three post-hoc pairwise comparisons were significant (SOFT-RIGID $\mathrm{p}=0.021$, MED-RIGID $\mathrm{p}=0.039$, NORM-RIGID $p=0.01$ ), where reduced stiffness was associated with $11-17 \%$ less negative collision work.

There were speed effects for both positive and negative work in the entire stance phase $(\mathrm{p} \leq 0.001$, $\eta_{p}^{2} \leq 0.742$ ). Fast walking was associated with $19 \%$ positive and $44 \%$ negative stance work compared to customary walking. Apart from the push-off subphase $\left(\mathrm{p} \geq 0.079, \eta_{p}^{2} \leq 0.255\right)$, all other sub-phases showed speed effects $(\mathrm{p}<0.001)$. Fast walking was also associated with increased sub-phase work: $81 \%$ greater negative collision work $\left(\mathrm{p}=0.001, \eta_{p}^{2}=0.749\right), 28 \%$ greater positive rebound work $\left(\mathrm{p}=0.001, \eta^{2}=0.642\right)$, and $69 \%$ greater positive preload work $(\mathrm{p}=0.001$, $\eta_{p}^{2}=0.642$ ) compared to customary walking.

There were no interaction effects $(\mathrm{p} \geq 0.804$, $\left.\eta_{p}^{2} \leq 0.029\right)$ in the entire stance phase. While the collision $\left(\mathrm{p} \geq 0.238, \quad \eta_{p}^{2} \leq 0.118\right)$, rebound $(\mathrm{p} \geq 0.244$, $\left.\eta_{p}^{2} \leq 0.117\right)$, and push-off $\left(\mathrm{p} \geq 0.245, \eta_{p}^{2} \leq 0.121\right)$ subphases were not significant, negative preload work showed an interaction effect $\left(\mathrm{p}=0.047, \eta_{p}^{2}=0.211\right)$. Simple main effects analysis revealed there were no stiffness $\left(\mathrm{p} \geq 0.567, \eta_{p}^{2} \leq 0.023\right)$ and speed effects $\left(\mathrm{p} \geq 0.256, \eta^{2} \leq 0.015\right)$ for negative preload work.

Work profiles of the sound ankle-foot (Additional file 1, Figure S1), knee (Additional file 2, Figure S2), hip (Additional file 3, Figure S3), and their written results (Additional file 4) are included as online additional material. 


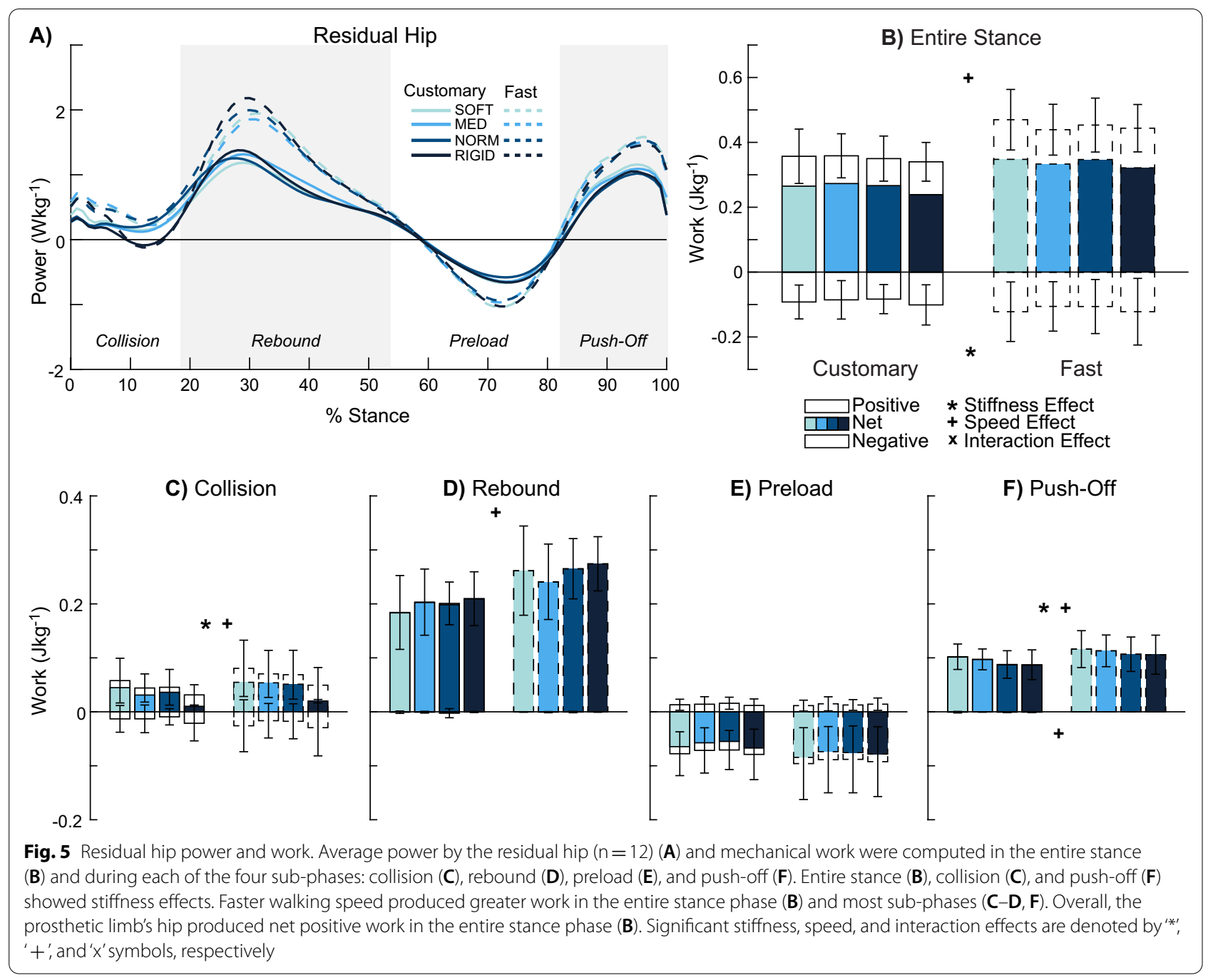

\section{Prosthesis analysis}

Additional analysis in the entire stance phase investigated the contribution of the pylon compression to the overall prosthetic work. There was a stiffness effect for pylon compression negative work during the entire stance phase $\left(\mathrm{p}<0.001, \eta_{p}^{2}=0.907\right.$, Fig. $\left.7 \mathrm{C}\right)$. All six posthoc pairwise comparisons were significant $(\mathrm{p} \leq 0.001)$, where reduced stiffness was associated with $18-229 \%$ more negative work.

There was also a speed effect for pylon compression negative work $\left(\mathrm{p}=0.004, \eta_{p}^{2}=0.541\right)$, where fast walking increased negative work by $29 \%$ compared to customary walking. Pylon compression negative work also showed an interaction effect $\left(\mathrm{p}=0.018, \eta_{p}^{2}=0.353\right)$. Simple main effects analysis revealed stiffness effects for both walking speeds $\left(\mathrm{p}<0.001, \eta_{p}^{2} \leq 0.559\right)$. Four pairwise comparisons were significant at each speed (SOFT-NORM $\mathrm{p}=0.003$, SOFT-RIGID $\mathrm{p}<0.001$, MED-RIGID $\mathrm{p}<0.001$, and NORM-RIGID $\mathrm{p}=0.003$ ), where reduced stiffness was associated with 52-204\% more negative work at customary walking and $44-252 \%$ more negative work at fast walking. Furthermore, simple main effects analysis for revealed speed effects in SOFT $\left(\mathrm{p}=0.006, \eta_{p}^{2}=0.083\right), \operatorname{MED}(\mathrm{p}=0.002$, $\left.\eta_{p}^{2}=0.101\right)$, and NORM ( $\left.\mathrm{p}=0.029, \eta_{p}^{2}=0.053\right)$ stiffness conditions, where fast walking was associated with $25-35 \%$ greater negative work.

A majority of the pylon compression's negative net work in the entire stance phase were absorbed in the collision phase (Fig. 7A). However, the pylon compression amounted to only $14 \%$ and $22 \%$ of the prosthesis' (i.e., all components distal to the socket, including the foot) net work in the entire stance and collision phases, respectively. The pylon compression's negative net work in the entire stance phase (Fig. 7C) corroborated with the pylon compression's force-displacement profiles (Fig. 7B): both the negative net work and the area under 


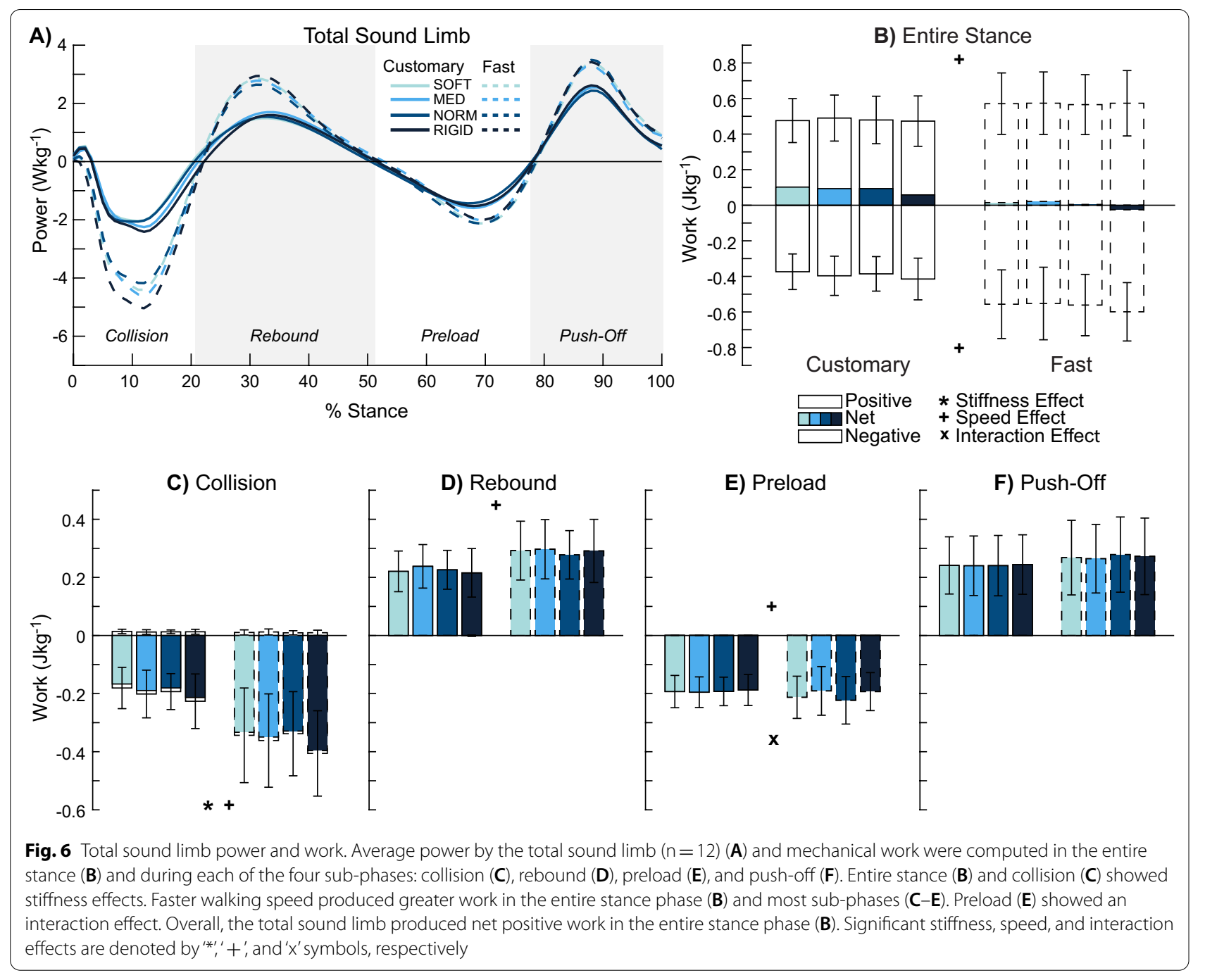

the force-displacement curves showed reducing stiffness led to greater negative net work.

\section{Discussion}

By partitioning the work done by the entire limb, this study assessed the effects of a SAP's longitudinal stiffness and walking speed on the energetic contributions of the prosthesis and intact joints. We tested the hypotheses that reducing SAP stiffness would: (1) increase the energy stored and returned by the prosthesis, (2) reduce the work demands on the residual knee and hip joints, and (3) that these stiffness effects are more pronounced at faster speeds. We found that the first hypothesis was partially supported in that reducing SAP stiffness increased prosthesis negative work during early stance, but did not affect positive work during late stance. Our last two hypotheses were not supported. Our study adds to the knowledge gained from previous studies using this dataset $[23,32]$ that with the main effects of reducing stiffness and increasing speed, the prosthesis showed a damping effect (greater energy loss) and led to greater push-off work at the residual hip joint.

Our first hypothesis was partially supported, in that reducing SAP stiffness increased negative work during collision, but did not increase positive work during pushoff-implying that the increased energy absorption during collision was not returned. Overall, the prosthesis showed a damping behavior in which the total positive work was less than $13 \%$ of the negative work. To further understand the sources of energy within the SAP-integrated prosthesis, we performed additional analyses to isolate the work contribution from the pylon. The pylon compressed mostly during early stance and its reduced stiffness increased the magnitude of negative work at both walking speeds. The pylon returned very little energy later in stance, with positive work less than 0.016 

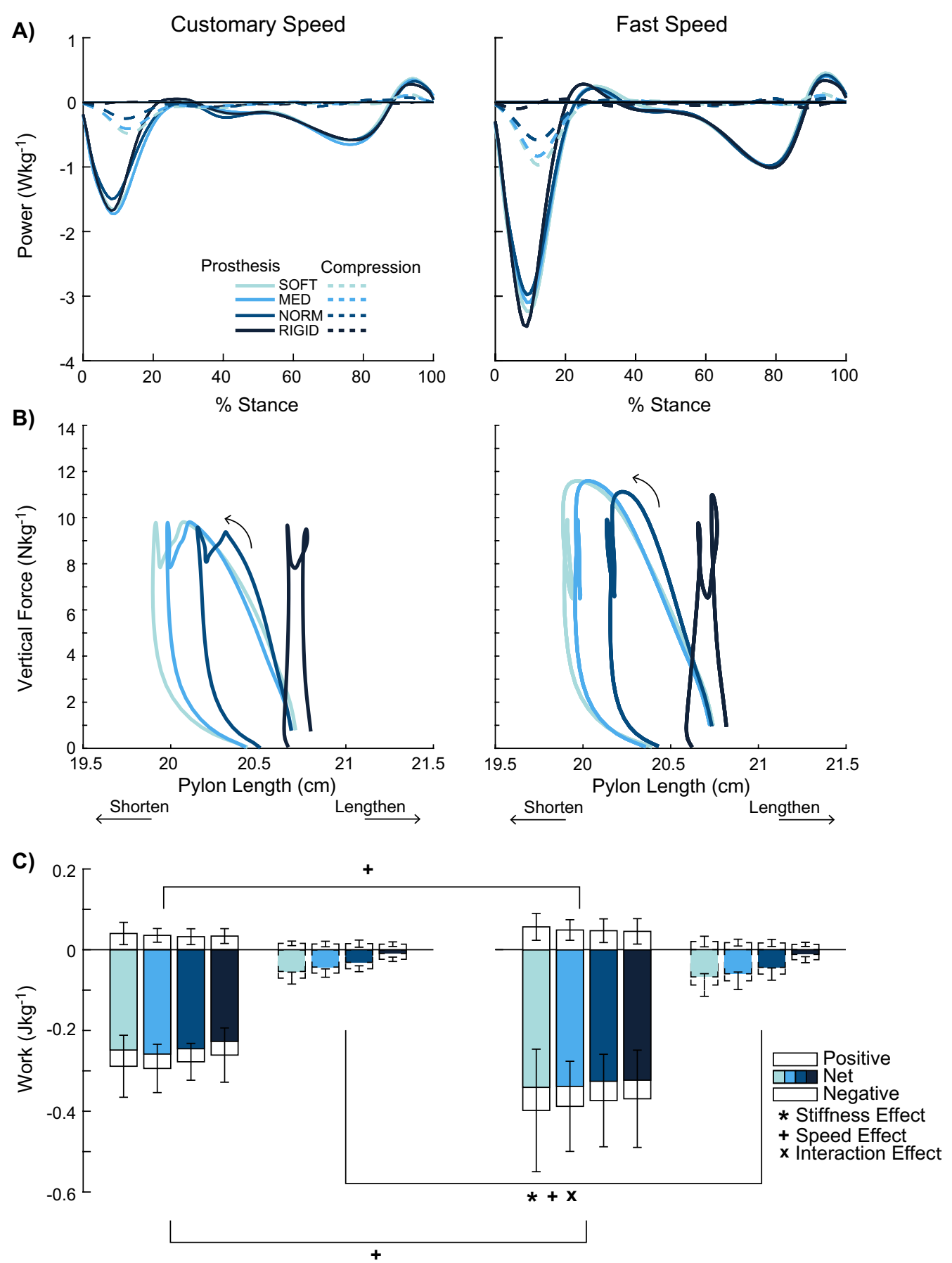

Fig. 7 Prosthesis analysis. Additional analysis examined the average power (A), force-displacement profiles (B), and mechanical work in the entire stance phase $(\mathbf{C})$ of the prosthesis and pylon compression in all levels of stiffness and speed. The force-displacement profiles (B) provide a visual representation of the net negative work produced from the pylon's compression (arrows indicate the time-progression during stance). The magnitude of net negative work increased as the pylon became less stiff. Significant stiffness, speed, and interaction effects are denoted by ${ }^{\prime * \prime \prime},+$, and ' $x$ ' symbols, respectively

$\mathrm{Jg}^{-1}$ across all conditions, resulting in largely negative net work that resembled the damping effect of the entire prosthesis. However, compared to the net work done by the entire prosthesis, the pylon only contributed $\sim 18 \%$ of the negative net work done by the prosthesis during stance, suggesting that the compressive pylon does not solely explain the prosthesis' damping effect. A potential explanation of the prosthesis' negative net work may be 
from the components distal to the pylon, specifically, the prosthetic foot, foot shell, and shoes. Although power and work from the prosthetic foot were not directly calculated, we can infer (i.e., prosthesis power minus pylon compression) that the remaining components played a role in the negative work (dissipation) from the prosthesis. In fact, previous bench characterization studies of prosthetic feet and footwear suggest overall damping behavior of these modular components [36, 43].

Our second hypothesis was not supported since there was increased work in the proximal intact joints in certain phases of stance, including greater residual knee negative work during collision and greater residual hip positive work during push-off (despite no change in prosthesis positive work). As the prosthesis produced more negative work during collision with reduced stiffness, the residual knee and hip joints redistributed their work output. Performing an extensor moment during collision, the residual knee joint negative work increased with reduced pylon stiffness, mirroring the greater negative work at the prosthesis albeit at a smaller magnitude work (14-24\% of the prosthesis). This finding may indicate that walking with an additional shock-absorbing component from the prosthesis may enhance the natural shock-absorbing function of the residual knee joint. Interestingly, with reduced pylon stiffness, the residual hip performed a flexor moment during collision and positive work increased in a similar magnitude comparable to the knee negative work, essentially opposing the residual knee's energetics. The functional role of this opposing residual hip-knee work during collision is currently unclear. One possibility is that these results may reflect the actions of multi-articular muscles that span these joints, but identifying specific sources of energy transfer across muscles may need additional computational models [44, 45]. Such musculoskeletal models may reveal insights that are inaccessible with the current study's analyses, such as how energy is transferred within the lower extremity (including to and from the prosthesis) due to the dynamic coupling of interconnected segments [44, 45]. Altogether, reducing pylon stiffness increased the energy absorption on the total prosthetic limb (summation of prosthesis, knee, and hip) during collision, consistent with a prior study [32].

While reducing pylon stiffness primarily affected the prosthesis work during the collision phase, the residual hip joint work output was altered at various phases of stance, specifically during push-off. Despite no significant changes in prosthesis push-off work (with reduced pylon stiffness), the residual hip joint increased its positive push-off work by $12 \%$. Interestingly, the residual hip joint total positive work did not change across the entire stance phase with varying pylon stiffness, indicating a temporal redistribution of positive work. One potential explanation for this temporal redistribution is that with greater negative work by the prosthesis (and the total limb) during collision, there was a greater demand for positive work later in stance (e.g., push-off) to preserve similar net work (i.e., close to zero) during stance. For example, the prosthesis increased the magnitude of negative work during collision by $0.027 \mathrm{Jkg}^{-1}$ (compared SOFT relative to RIGID stiffness conditions), while the residual hip joint generated $0.012 \mathrm{Jkg}^{-1}$ more positive push-off work to partially make up for the increased energy loss during collision. Currently, it is unclear whether such temporal redistribution of hip work is beneficial to the user, or whether such patterns may affect stability mechanisms, or exaggerate a hip powering strategy during push-off that are common in individuals with lower-limb amputations [46, 47].

While not included in our original hypotheses, we found that reducing pylon stiffness reduced collision work on the sound limb, consistent with a prior study [32]. Individuals with a unilateral amputation typically have greater sound limb collision work compared to healthy control participants $[26,48]$ and has been implied as a potential risk factor for joint osteoarthritis [49-51]. An association between reduced prosthetic limb push-off work and increased sound limb collision work has been suggested [26], where reduced prosthetic limb push-off would lead to an insufficient redirection of the center-of-mass velocity that leads to greater absorption requirement on the sound limb during the step-to-step transition. Consequently, lower-limb prostheses that contribute to push-off by passively returning elastic energy $[9,49]$ or through actively generating power [11] have demonstrated reductions in sound limb loading and collision work. We found in our study that the sound limb collision work was reduced by $11-17 \%$ with the least stiff conditions, which coincided with greater prosthetic limb collision work and not from increased push-off work. In comparison, a prior study found $22-27 \%$ reduction in sound limb collision work when individuals walked (at comparable speeds to our studies) with a powered prosthesis (compared to an unpowered prosthesis) aided by push-off power generation [11]. While the mechanisms of the inverse relationship between prosthetic and sound limb collision work in our study are currently unclear, these results are consistent with a recent study that found prosthetic limb collision work are negatively correlated to sound limb collision [52]. Future studies should examine the role of the prosthetic limb's negative work on reducing sound limb collision, which may lead to encouraging clinical implications such as preserved health and integrity of intact limb's joint tissue [50]. 
Based on the results of this study and previous studies $[19,22,23,32]$, future research may need to consider the potential trade-offs in the benefits and adaptive compensations to support the use and prescription of SAPs. The user may benefit from walking with SAPs as they absorb energy [32] to reduce impact peak forces during early stance [22] with less collision work on the sound limb [32]. In other words, SAPs could assist in weight acceptance on the prosthetic limb, as well as the sound limb. However, walking with SAPs could increase the push-off work demands at the residual hip joint, potentially to balance out the greater negative work done on the prosthesis earlier in stance (collision), which may theoretically increase the metabolic cost [26]. Interestingly, a prior study found that SAPs can reduce metabolic energy cost of walking [53], even though our study found that SAPs absorb more energy. Thus, it is possible that increased prosthetic energy absorption may even reduce metabolic cost, perhaps through decreased collision on the sound limb-but this is merely speculation and further research is needed to unravel the effects of SAPs on the mechanics and metabolic demands of walking. Future studies should also consider the potential benefit of SAPs during tasks that require greater energy dissipation (e.g., downhill walking or stepping down curbs) [19] or in other tasks that require greater attenuation of impact forces (e.g., walking with a weighted backpack) [54-56]. A comprehensive investigation analyzing the effect of SAPs in a wide variety of walking tasks is necessary to support the use and clinical prescription of SAPs.

Potential limitations are specified in this study. The first limitation is the energy lost at the residuum-socket interface cannot be quantified due to our methodology of calculating power of all components below a reference segment (i.e., prosthetic socket) [38]. The second limitation of this study is the power and work profiles of the prosthetic foot and shoes cannot be isolated using the current protocol. However, with our additional prosthesis analysis, we deduced the amount of work produced by the prosthetic foot and shoe combination. Another limitation includes having a short familiarization period (at least $5 \mathrm{~min}$ ) to properly adjust to each prosthetic condition. Future studies may involve more detailed computational models of the prosthetic components integrated with a muscle-driven model of the intact joints, which could further reveal the energy transfer within and across the prosthesis and the intact muscles.

\section{Conclusion}

In our study, faster walking speeds significantly produced larger magnitudes of mechanical work. Generally, the least stiff SAP (compared to rigid) increased the magnitude of prosthesis negative work during collision by $0.027 \mathrm{Jkg}^{-1}$ (rigid versus least stiff SAP), without affecting the positive work (energy return) later in stance, which implies a damping effect. A portion of this energy loss during collision was partially offset by an increase in the residual hip positive work $(0.012$ $\mathrm{Jkg}^{-1}$ increase in the least stiff versus rigid SAP) later in stance during push-off. We also observed 11-17\% reduction in sound limb collision work with the least stiff prosthesis, although the mechanism driving this reduction is currently unclear. While this reduction in sound limb work may imply favorable clinical implications, it is unclear whether the use of SAPs is entirely beneficial during walking. Future studies are warranted to investigate whether SAPs could provide additional user benefits in tasks that require greater energy dissipation (e.g., downhill walking, stepping down curbs) or tasks that require greater attenuation of impact forces (e.g., load carriage, walking on uneven terrain).

Abbreviation

SAP: Shock-absorbing pylon.

\section{Supplementary Information}

The online version contains supplementary material available at https://doi. org/10.1186/s12984-021-00939-8.

\begin{abstract}
Additional file 1. Sound ankle-foot power and work. Average power by the sound ankle-foot $(n=12)(A)$ and mechanical work were computed in the entire stance $(B)$ and during each of the four sub-phases: collision (C), rebound (D), preload (E), and push-off (F). Faster walking speed produced greater magnitudes of work in the entire stance phase (B) and collision (C). Entire stance (B), rebound (D), preload (E), and push-off(F) showed interaction effects. Overall, the sound ankle-foot produced net negative work in the entire stance phase (B). Significant stiffness, speed, and interaction effects are denoted by ${ }^{\prime * \prime \prime},+$ ', and ' $x$ ' symbols, respectively.
\end{abstract}

Additional file 2. Sound knee power and work. Average power by the sound knee $(n=12)(A)$ and mechanical work were computed in the entire stance (B) and during each of the four sub-phases: collision (C), rebound (D), preload (E), and push-off (F). Faster walking speed produced greater magnitudes of work across the entire stance phase (B) and subphases (C-F). Preload (E) showed an interaction effect. Overall, the sound limb's knee produced net positive work across the entire stance phase (B) in all stiffness and speed conditions. Significant stiffness, speed, and interaction effects are denoted by ${ }^{\prime * \prime \prime},+$ ', and ' $x^{\prime}$ 'symbols, respectively.

Additional file 3. Sound hip power and work. Average power by the sound hip $(n=12)(A)$ and mechanical work were computed in the entire stance $(B)$ and during each of the four sub-phases: collision (C), rebound (D), preload (E), and push-off (F). Collision (C) showed a stiffness effect. Faster walking speed produced greater work in the entire stance phase (B) and most sub-phases (C-D, F). Overall, the sound limb's knee produced net positive work in the entire stance phase (B). Significant stiffness, speed, and interaction effects are denoted by ${ }^{\prime * \prime},{ }^{\prime}+{ }^{\prime}$, and ' $x^{\prime}$ symbols, respectively.

Additional file 4. Results from sound limb ankle-foot, knee, and hip.

\section{Acknowledgements}

The authors would like to acknowledge Dr. Erin Boutwell and Ms. Rebecca Stine for their contribution to the original study. 


\section{Authors' contributions}

SG and MM performed the initial study conception and supervised the data collections. All authors conceived the retrospective study and analyses methods. JM and KT performed the data analyses. JM drafted the manuscript and all co-authors read, revised, and approved the final manuscript.

\section{Funding}

This work was supported in part by SPiRE Award \#121 RX001363 from the U.S Department of Veterans Affairs, Rehabilitation Research and Development Service awarded to SG, and by the Center of Research in Human Movement Variability of the University of Nebraska at Omaha, NIH (P20GM109090) awarded to KT.

\section{Availability of data and materials}

The data generated or analyzed during this study are available from the corresponding author on reasonable request.

\section{Declarations}

\section{Ethics approval and consent to participate}

This study was approved by the Northwestern University Institutional Review Board (project number STU00037607).

\section{Consent for publication}

Not applicable.

\section{Competing interests}

The authors declare that they have no competing interests.

\section{Author details}

1 Department of Biomechanics, University of Nebraska at Omaha, Omaha, NE USA. ${ }^{2}$ Department of Physical Medicine and Rehabilitation, Feinberg School of Medicine, Northwestern University, Chicago, IL, USA. ${ }^{3}$ Department of Biomedical Engineering, Northwestern University, Evanston, IL, USA. ${ }^{4}$ Jesse Brown VA Medical Center, Chicago, IL, USA.

Received: 16 October 2020 Accepted: 8 September 2021 Published online: 21 September 2021

\section{References}

1. Davies B, Datta D. Mobility outcome following unilateral lower limb amputation. Prosthet Orthot Int. 2003;27(3):186-90.

2. Norvell DC, Turner AP, Williams RM, Hakimi KN, Czerniecki JM. Defining successful mobility after lower extremity amputation for complications of peripheral vascular disease and diabetes. J Vasc Surg. 2011;54(2):412-9.

3. Sinha R, van den Heuvel WJ, Arokiasamy P. Factors affecting quality of life in lower limb amputees. Prosthet Orthot Int. 2011;35(1):90-6.

4. Wurdeman SR, Stevens PM, Campbell JH. Mobility Analysis of AmpuTees (MAAT I): quality of life and satisfaction are strongly related to mobility for patients with a lower limb prosthesis. Prosthet Orthot Int. 2018;42(5):498-503.

5. Legro MW, Reiber G, del Aguila M, Ajax MJ, Boone DA, Larsen JA, et al. Issues of importance reported by persons with lower limb amputations and prostheses. J Rehabil Res Dev. 1999;36(3):155-63.

6. Postema K, Hermens HJ, de Vries J, Koopman HF, Eisma WH. Energy storage and release of prosthetic feet. Part 2: subjective ratings of 2 energy storing and 2 conventional feet, user choice of foot and deciding factor. Prosthet Orthot Int. 1997;21(1):28-34.

7. Klute GK, Kallfelz CF, Czerniecki JM. Mechanical properties of prosthetic limbs: adapting to the patient. J Rehabil Res Dev. 2001;38(3):299-307.

8. Honert EC, Bastas G, Zelik KE. Effect of toe joint stiffness and toe shape on walking biomechanics. Bioinspir Biomim. 2018;13(6): 066007.

9. Childers WL, Takahashi KZ. Increasing prosthetic foot energy return affects whole-body mechanics during walking on level ground and slopes. Sci Rep. 2018;8(1):5354.

10. Fey NP, Klute GK, Neptune RR. Optimization of prosthetic foot stiffness to reduce metabolic cost and intact knee loading during below-knee amputee walking: a theoretical study. J Biomech Eng. 2012;134(11): 111005.

11. Herr HM, Grabowski AM. Bionic ankle-foot prosthesis normalizes walking gait for persons with leg amputation. Proc Biol Sci. 2012;279(1728):457-64.

12. Montgomery JR, Grabowski AM. Use of a powered ankle-foot prosthesis reduces the metabolic cost of uphill walking and improves leg work symmetry in people with transtibial amputations. J R Soc Interface. 2018. https://doi.org/10.1098/rsif.2018.0442.

13. Ingraham KA, Choi H, Gardinier ES, Remy CD, Gates DH. Choosing appropriate prosthetic ankle work to reduce the metabolic cost of individuals with transtibial amputation. Sci Rep. 2018;8(1):15303.

14. Quesada RE, Caputo JM, Collins SH. Increasing ankle push-off work with a powered prosthesis does not necessarily reduce metabolic rate for transtibial amputees. J Biomech. 2016;49(14):3452-9.

15. Shepherd MK, Azocar AF, Major MJ, Rouse EJ. Amputee perception of prosthetic ankle stiffness during locomotion. J Neuroeng Rehabil. 2018;15(1):99.

16. Hedrick EA, Malcolm P, Wilken JM, Takahashi KZ. The effects of ankle stiffness on mechanics and energetics of walking with added loads: a prosthetic emulator study. J Neuroeng Rehabil. 2019;16(1):148.

17. Major MJ, Twiste M, Kenney LP, Howard D. The effects of prosthetic ankle stiffness on ankle and knee kinematics, prosthetic limb loading, and net metabolic cost of trans-tibial amputee gait. Clin Biomech (Bristol, Avon). 2014;29(1):98-104.

18. Major MJ, Twiste M, Kenney LP, Howard D. The effects of prosthetic ankle stiffness on stability of gait in people with transtibial amputation. J Rehabil Res Dev. 2016;53(6):839-52.

19. Miller LA, Childress DS. Analysis of a vertical compliance prosthetic foot. J Rehabil Res Dev. 1997;34(1):52-7.

20. Berge JS, Czerniecki JM, Klute GK. Efficacy of shock-absorbing versus rigid pylons for impact reduction in transtibial amputees based on laboratory, field, and outcome metrics. J Rehabil Res Dev. 2005;42(6):795-808.

21. Farrar $M$, Thomas E. A systematic review of shock-attenuating componentry for lower limb amputees. Prosthet Orthot Int. 2018;42(4):367-77.

22. Gard SA, Konz RJ. The effect of a shock-absorbing pylon on the gait of persons with unilateral transtibial amputation. J Rehabil Res Dev. 2003:40(2):109-24.

23. Boutwell E, Stine R, Gard S. Shock absorption during transtibial amputee gait: does longitudinal prosthetic stiffness play a role? Prosthet Orthot Int 2017;41(2):178-85.

24. Pew C, Klute GK. Second generation prototype of a variable stiffness transverse plane adapter for a lower limb prosthesis. Med Eng Phys. 2017:49:22-7

25. Pew C, Segal AD, Neptune RR, Klute GK. Ideal operating conditions for a variable stiffness transverse plane adapter for individuals with lower-limb amputation. J Biomech. 2019;96: 109330.

26. Adamczyk PG, Kuo AD. Mechanisms of gait asymmetry due to push-off deficiency in unilateral amputees. IEEE Trans Neural Syst Rehabil Eng. 2015;23(5):776-85.

27. Honert EC, Zelik KE. Foot and shoe responsible for majority of soft tissue work in early stance of walking. Hum Mov Sci. 2019;64:191-202.

28. Baines PM, Schwab AL, van Soest AJ. Experimental estimation of energy absorption during heel strike in human barefoot walking. PLoS ONE. 2018;13(6): e0197428.

29. Papachatzis N, Malcolm P, Nelson CA, Takahashi KZ. Walking with added mass magnifies salient features of human foot energetics. J Exp Biol. 2020. https://doi.org/10.1242/jeb.207472.

30. DickTJM, Clemente CJ, Punith LK, Sawicki GS. Series elasticity facilitates safe plantar flexor muscle-tendon shock absorption during perturbed human hopping. Proc Biol Sci. 2021;288(1947):20210201.

31. Maharaj JN, Cresswell AG, Lichtwark GA. Tibialis anterior tendinous tissue plays a key role in energy absorption during human walking. J Exp Biol. 2019. https://doi.org/10.1242/jeb.191247.

32. Major MJ, Zavaleta JL, Gard SA. Does decreasing below-knee prosthesis pylon longitudinal stiffness increase prosthetic limb collision and pushoff work during gait? J Appl Biomech. 2019. https://doi.org/10.1123/jab. 2019-0043.

33. Fey NP, Klute GK, Neptune RR. The influence of energy storage and return foot stiffness on walking mechanics and muscle activity in below-knee amputees. Clin Biomech (Bristol, Avon). 2011;26(10):1025-32. 
34. Czerniecki JM, Gitter A, Munro C. Joint moment and muscle power output characteristics of below knee amputees during running: the influence of energy storing prosthetic feet. J Biomech. 1991;24(1):63-75.

35. Shell CE, Segal AD, Klute GK, Neptune RR. The effects of prosthetic foot stiffness on transtibial amputee walking mechanics and balance control during turning. Clin Biomech (Bristol, Avon). 2017;49:56-63.

36. Major MJ, Scham J, Orendurff M. The effects of common footwear on stance-phase mechanical properties of the prosthetic foot-shoe system. Prosthet Orthot Int. 2018:42(2):198-207.

37. Kadaba MP, Ramakrishnan HK, Wootten ME. Measurement of lower extremity kinematics during level walking. J Orthop Res. 1990;8(3):383-92.

38. Takahashi KZ, Kepple TM, Stanhope SJ. A unified deformable (UD) segment model for quantifying total power of anatomical and prosthetic below-knee structures during stance in gait. J Biomech. 2012;45(15):2662-7.

39. Buczek FL, Kepple TM, Siegel KL, Stanhope SJ. Translational and rotational joint power terms in a six degree-of-freedom model of the normal ankle complex. J Biomech. 1994;27(12):1447-57.

40. Zelik KE, Takahashi KZ, Sawicki GS. Six degree-of-freedom analysis of hip, knee, ankle and foot provides updated understanding of biomechanical work during human walking. J Exp Biol. 2015;218(Pt 6):876-86.

41. Zelik KE, Kuo AD. Human walking isn't all hard work: evidence of soft tissue contributions to energy dissipation and return. J Exp Biol. 2010;213(Pt 24):4257-64.

42. Hedrick EA, Stanhope SJ, Takahashi KZ. The foot and ankle structures reveal emergent properties analogous to passive springs during human walking. PLOS ONE. 2019;14(6): e0218047.

43. Major MJ, Johnson WB, Gard SA. Interrater reliability of mechanical tests for functional classification of transtibial prosthesis components distal to the socket. J Rehabil Res Dev. 2015;52(4):467-76.

44. Pickle NT, Grabowski AM, Jeffers JR, Silverman AK. The functional roles of muscles, passive prostheses, and powered prostheses during sloped walking in people with a transtibial amputation. J Biomech Eng. 2017. https://doi.org/10.1115/1.4037938.

45. Fey NP, Klute GK, Neptune RR. Altering prosthetic foot stiffness influences foot and muscle function during below-knee amputee walking: a modeling and simulation analysis. J Biomech. 2013;46(4):637-44.
46. Bateni $\mathrm{H}$, Olney S. Kinematic and kinetic variations of below-knee amputee gait. J Prosthet Orthot. 2002;14(1):2-10.

47. Silverman AK, Fey NP, Portillo A, Walden JG, Bosker G, Neptune RR. Compensatory mechanisms in below-knee amputee gait in response to increasing steady-state walking speeds. Gait Posture. 2008;28(4):602-9.

48. Houdijk H, Pollmann E, Groenewold M, Wiggerts H, Polomski W. The energy cost for the step-to-step transition in amputee walking. Gait Posture. 2009;30(1):35-40.

49. Morgenroth DC, Segal AD, Zelik KE, Czerniecki JM, Klute GK, Adamczyk $P G$, et al. The effect of prosthetic foot push-off on mechanical loading associated with knee osteoarthritis in lower extremity amputees. Gait Posture. 2011;34(4):502-7.

50. Morgenroth DC, Gellhorn AC, Suri P. Osteoarthritis in the disabled population: a mechanical perspective. PM R. 2012;4(5 Suppl):S20-7.

51. Russell Esposito E, Wilken JM. Biomechanical risk factors for knee osteoarthritis when using passive and powered ankle-foot prostheses. Clin Biomech (Bristol, Avon). 2014;29(10):1186-92.

52. Chieu K, Greiner A, Chang Y, Childers L, editors. Sound limb impact is predicted by both the collisional and propulsive work from the amputated limb. American Academy of Orthotists \& Prosthetists; 2018; Chicago, IL.

53. Buckley JG, Jones SF, Birch KM. Oxygen consumption during ambulation: comparison of using a prosthesis fitted with and without a tele-torsion device. Arch Phys Med Rehabil. 2002;83(4):576-80.

54. Birrell SA, Hooper RH, Haslam RA. The effect of military load carriage on ground reaction forces. Gait Posture. 2007;26(4):611-4.

55. Schnall BL, Hendershot BD, Bell JC, Wolf EJ. Kinematic analysis of males with transtibial amputation carrying military loads. J Rehabil Res Dev. 2014;51(10):1505-14.

56. Schnall BL, Dearth CL, Elrod JM, Golyski PR, Koehler-McNicholas SR, Ray SF, et al. A more compliant prosthetic foot better accommodates added load while walking among Servicemembers with transtibial limb loss. J Biomech. 2020;98: 109395.

\section{Publisher's Note}

Springer Nature remains neutral with regard to jurisdictional claims in published maps and institutional affiliations.
Ready to submit your research? Choose BMC and benefit from:

- fast, convenient online submission

- thorough peer review by experienced researchers in your field

- rapid publication on acceptance

- support for research data, including large and complex data types

- gold Open Access which fosters wider collaboration and increased citations

- maximum visibility for your research: over 100M website views per year

At BMC, research is always in progress.

Learn more biomedcentral.com/submissions 